\title{
A Retrospective Analysis for Different Routes of Administration in Mice-Percutaneous Retro-Orbital, Jugular Catheter, Tail Vein and Femoral Cut Down Injections
}

\author{
Priyanka Prathipati1 ${ }^{*}$, Cristian Rodriguez-Aguayo ${ }^{2,3}$, Brian L Walton1, Anil K. Sood $3,4,5$, \\ Jamieson Greaver6, Christopher F. Janssen ${ }^{6}$, Gabriel Lopez-Berestein ${ }^{2,3,4}$
}

${ }^{1}$ Department of Advanced Cardiopulmonary Therapies and Transplantation, Center for Advanced Heart Failure, University of Texas Health Science Center at Houston, Houston, TX, USA

${ }^{2}$ Department of Experimental Therapeutics, University of Texas M.D. Anderson Cancer Center, Houston, TX, USA

${ }^{3}$ The Center for RNA Interference and Non-Coding RNA, University of Texas M.D. Anderson Cancer Center, Houston, TX, USA

${ }^{4}$ Department of Cancer Biology, University of Texas M.D. Anderson Cancer Center, Houston, TX, USA

${ }^{5}$ Department of Gynecology Oncology \& Reproductive Medicine, University of Texas M.D. Anderson Cancer Center, Houston, TX, USA

${ }^{6}$ Interdisciplinary Research, Center for Laboratory Animal Medicine and Care, University of Texas Health Science Center at Houston, Houston, TX, USA

Email: ${ }^{\star P r i y a n k a . P r a t h i p a t i @ u t h . t m c . e d u ~}$

How to cite this paper: Prathipati, P., Rodriguez-Aguayo, C., Walton, B.L., Sood, A.K., Greaver, J., Janssen, C.F. and Lopez-Berestein, G. (2020) A Retrospective Analysis for Different Routes of Administration in Mice-Percutaneous Retro-Orbital, Jugular Catheter, Tail Vein and Femoral Cut Down Injections. Journal of Biosciences and Medicines, 8, 131-141.

https://doi.org/10.4236/jbm.2020.89011

Received: May 18, 2020

Accepted: September 14, 2020

Published: September 17, 2020

Copyright () 2020 by author(s) and Scientific Research Publishing Inc. This work is licensed under the Creative Commons Attribution International License (CC BY 4.0).

http://creativecommons.org/licenses/by/4.0/

\section{(c) (i) Open Access}

\begin{abstract}
Liposomes effectively transport fatty proteins to targeted tissues. Laboratory experiments use multiple methods to administer liposomes, but comparison of these methods is not available. In this retrospective study, we characterized and compared four intravenous administration routes (tail vein, jugular catheter, femoral vein and percutaneous retro-orbital injections) in murine models. ApoE ${ }^{-/}$mice were used to compare administration routes. Results indicate that the jugular catheter route delivered the highest amount of liposomes to tissues due to longer period of injections compared to other routes; however, this route failed to remain patent for $8 / 10$ animals. Delivery via tail vein, femoral vein and percutaneous retro-orbital injections resulted in similar accumulation in the organs. When including technical difficulty and expense, percutaneous retro-orbital injections of liposomes are the most convenient and efficacious approach.
\end{abstract}

\section{Keywords}

Femoral Vein, Jugular Catheter, Liposomes, Retro-Orbital, Tail Vein 


\section{Introduction}

The route of drug delivery is a significant aspect of the experimental design. Absorption, distribution, metabolism and excretion of the investigating compound along with dose and frequency of administration must be known to optimize the efficacy of experiments in laboratory animals [1]. There are several common intravenous (IV) routes used (Table 1); however, data were lacking as to the comparison of routes to identify the ideal delivery in the murine model. The predominant modality is IV as it bypasses the challenge of solute absorption [1]. When investigators are selecting an experimental design they must consider the benefits and challenges of the route itself. The four main administration routes are detailed below and summarized in Table 2 .

The lateral tail vein is often utilized for IV injections, as it is a direct route and used in past experiments. When trying to compare data, often times the same protocol is utilized. This route can be used to inject cancerous cells unlike the other routes. Unfortunately, this route is also technically challenging, requiring the use of an experienced technician or researcher to avoid multiple injection attempts and/or incomplete drug delivery [2]. Further, in case of pigmented, very young or transgenic mice, this route of administration is complicated by the

Table 1. Different route of administrations and their drug entry site. Drug can be introduced into the body through various routes of administration (1).

\begin{tabular}{|c|c|}
\hline Route of administration & Injection site \\
\hline Oral & Mouth \\
\hline Gastric gavage & Stomach \\
\hline Intravenous & Blood vessel \\
\hline Intramuscular & Muscle \\
\hline $\begin{array}{l}\text { Epicutaneous } \\
\text { Intradermal } \\
\text { Subcutaneous } \\
\text { Transdermal }\end{array}$ & Skin \\
\hline $\begin{array}{c}\text { Transcorneal } \\
\text { Intraocular } \\
\text { Percutaneous retroorbital }\end{array}$ & Eye \\
\hline Intracerebral & Brain \\
\hline Epidural & Dura mater \\
\hline Intrathecal & Spinal cord \\
\hline Intraperitoneal & Peritoneal cavity \\
\hline Intranasal & Nose \\
\hline Intratracheal & Trachea \\
\hline Intraosseous & Marrow cavity \\
\hline
\end{tabular}


Table 2. Comparison of different intravenous routes of administration. Advantages and disadvantages of different IV routes of administration.

\begin{tabular}{|c|c|c|c|}
\hline Route & Anesthesia & Pros & Cons \\
\hline Tail vein & $\mathrm{X}$ & Inexpensive & $\begin{array}{l}\text { - Restraining and heating required, stress to the animal } \\
\text { - Difficult to inject viscous substances } \\
\text { - Technically challenging (especially for dark skin animals) } \\
\text { - Greater chances of failure } \\
\text { - More chances of bruising }\end{array}$ \\
\hline $\begin{array}{l}\text { Femoral } \\
\text { cut down }\end{array}$ & $\sqrt{ }$ & $\begin{array}{l}\text { Accurate delivery } \\
\text { into the veins. }\end{array}$ & $\begin{array}{l}\text { - Difficult to access the site of injection } \\
\text { - Limited number of injections } \\
\text { - Not useful for long-term studies } \\
\text { - Technically challenging }\end{array}$ \\
\hline $\begin{array}{l}\text { Jugular } \\
\text { catheter }\end{array}$ & $\sqrt{ }$ & $\begin{array}{c}\text { Easy access with the catheter } \\
\text { for IV injections }\end{array}$ & $\begin{array}{l}\text { - Expensive } \\
\text { - Requires invasive surgery to insert the catheter } \\
\text { - Animal needs recovery time } \\
\text { - Catheter should be maintained carefully by flushing regularly } \\
\text { - Not useful for long-term studies } \\
\text { - More chances of internal leakage from the catheter } \\
\text { - May need to house animals individually }\end{array}$ \\
\hline Retro-orbital & $\sqrt{ }$ & $\begin{array}{l}\text { - Less challenging than tail vein } \\
\text { - More chances of successful delivery } \\
\text { - Less stressful to the animal } \\
\text { - Useful for chronic and long-term studies } \\
\text { - Less chances of bruising }\end{array}$ & $\begin{array}{l}\text { - Personnel needs training to inject accurately } \\
\text { - Institutional animal welfare committee should approve the } \\
\text { process }\end{array}$ \\
\hline
\end{tabular}

reduced size and/or altered morphology [3]. For visualization of the vein and vasodilation, the tail is either immersed in warm water or placed under a heat lamp [4]. Because this method requires mechanical restraints, distress is introduced as well which could alter hormonal responses.

Catheterization is another technically challenging route. Jugular catheterization is recommended for compound infusions whereas carotid catheterization is used for blood withdrawal [5]. Catheterization helps in precisely delivering the drug into circulation or to localized areas. Use of IV catheters requires more caution and maintenance to avoid infection. In addition, insertion of a catheter requires invasive surgery and animal recovery time, which add expense and time. Of note, mice with catheters should be housed separately to avoid damage to the catheter by other cage mates; the isolation may also affect experiments.

The femoral vein is a less popular administration route as compared to tail vein injections. Use of the femoral vein cut down method ensures the investigational compound directly enters the bloodstream. Unlike the tail vein route, the femoral vein cut down requires the use of anesthesia. In the case of femoral cut down, only two injections are possible due to making incisions in the veins limits repeated injections and the availability of only two femoral veins restricts this route.

Injections via the retro-orbital vascular sinus do not depend on peripheral vasoconstriction [6]. This modality is less technically challenging as compared to 
the other three routes and can be performed under inhalation anesthesia. The animal thereby undergoes less stress. Unfortunately, few studies have used retro-orbital injections [2] [7] [8] [9] [10]. Gene therapy [11] and adenoviruses [12] experiments have utilized this method with great success. Local irritation is noted in prior research, depending on the substance injected; this route is more preferable when injecting non-tumorigenic compounds [9] [10]. Some of the cautions to be taken with the retro-orbital route include slow administration of the substance, utilization of smaller needles (preferably smaller than $27 \mathrm{G}$ ), and injectable must be less than $5 \mathrm{ml} / \mathrm{kg}$ body weight [3].

To compare these common, but different, IV routes, investigators sought to study the effectiveness and utility of each route by tracking the accumulation of fluorescent labelled liposomes in targeted organs in a retrospective study.

\section{Materials and Methods}

\subsection{Ethical Statement}

The animal experiments were approved by the Animal Welfare Committee and Institutional Animal Care and Use Committee at the University of Texas Health Science Center at Houston (AWC-17-0080). Mice were obtained from Jackson Laboratory (Bar Harbor, ME). Mice were housed in controlled environment with free access to food and tap water. Administration of liposomes via each method are detailed below and summarized in Table 3.

\subsection{Liposomal SiRNA Preparation}

Control siRNA (Dharmacon, La Fayette, CO) and liposomes were prepared with 7:3 molar ratio of the lipids DMPC (1,2-dimyristoyl-sn-glycero-3-phosphocholine) and DMPG (1,2-dimyristoyl-sn-glycero-3-phosphoglycerol) with quantum dots, tween 20, and excess tertiary butanol. The mixture was lyophilized, and stored at $-20^{\circ} \mathrm{C}$ until use as previously described [13] [14]. Lyophilized powder was hydrated with $1 \times$ phosphate-buffered saline (PBS) at the concentration of $100 \mu \mathrm{g} / \mathrm{ml}$; $100 \mu \mathrm{l}$ of this stock was used as the solution for the liposome solute injections.

Table 3. Summary of injections to animals through different routes. This table summarizes the number of injections and volume of liposomes received by each experimental group.

\begin{tabular}{|c|c|c|c|c|}
\hline $\begin{array}{c}\text { Route of } \\
\text { administration }\end{array}$ & $\begin{array}{l}\text { Number of } \\
\text { Injections }\end{array}$ & $\begin{array}{l}\text { Total volume } \\
\text { of injection }(\mu \mathrm{l})\end{array}$ & Age (weeks) & Special Notes \\
\hline Percutaneous retro-orbital & 2 & 200 & 10 & \\
\hline Jugular catheter & 6 & 600 & 10 & $\begin{array}{l}\text { Injections were continued as long as possible to access } \\
\text { duration of catheter patency. Each mice with the catheter } \\
\text { costs } \$ 117 \text { more than the regular mice. These mice needs } \\
\text { to be individually housed which makes it expensive } \\
\text { than the other routes }\end{array}$ \\
\hline Tail vein & 2 & 200 & 10 & \\
\hline Femoral cut down & 2 & 200 & 16 & Not more than two injections possible through this route. \\
\hline
\end{tabular}


All liposomes were reconstituted with PBS at room temperature and injected because fewer side effects are observed in animals when the injection substance is near body temperature [15] [16].

\subsection{Tail Vein Group Experiments}

Male $\mathrm{ApoE}^{-/-}$mice $(\mathrm{C} 57 \mathrm{BL} / 6$ background) of 6 weeks of age $(\mathrm{n}=5)$ were on regular chow until 10 weeks of age. Two injections were administered on their $11^{\text {th }}$ week (day 0 and 3 ) through tail vein. At the end of 11 weeks, the mice were euthanized, and tissues (liver, spleen and lung) were collected.

\subsection{Jugular Catheterization Group Experiments}

Male ApoE ${ }^{-/}$mice $(\mathrm{C} 57 \mathrm{BL} / 6$ background) of 6 weeks of age $(\mathrm{n}=10)$ were kept on a high fat diet until 10 weeks of age. Catheters were maintained as per instructions [5]. Mice were injected with two liposomal injections per week for three weeks. At the end of three weeks, mice were euthanized and tissues (liver, spleen and lung) were collected.

\subsection{Femoral Cut Down Group Experiments}

Male $\mathrm{ApoE}^{-/-}$mice $(\mathrm{C} 57 \mathrm{BL} / 6$ background) aged 16 weeks $(\mathrm{n}=16)$ were on regular diet and injected with liposomes through femoral vein. The mice were anesthetized with $2 \%$ isoflurane and hair was removed from the femoral area. Vasodilator (topical lidocaine) was applied to the femoral vein and small incision was made for femoral vein visualization. Two IV injections were administered (day 0 and 3) containing liposomal control siRNA incorporated with quantum dots (QD) (each dose $=10 \mu \mathrm{g}$ in $100 \mu \mathrm{L}$ PBS). The incisions were closed by applying small amount of GLUture (Abbott Laboratories, Abbott Park, IL). On day 7, the mice were anesthetized and euthanized, and tissues (liver, spleen and lung) were collected.

\subsection{Percutaneous Retro-Orbital Group Experiments}

Male ApoE ${ }^{-/}$mice (C57BL/6 background) of 6 weeks of age $(n=5)$ were on regular chow until 10 weeks of age. Retro-orbital injections in mice followed a standardized protocol [2] [6]. Mice were injected with two liposomal injections (day 0 and 3) at 11 weeks of age. At the end of 11 weeks, mice were euthanized and tissues (liver, spleen and lung) were collected.

\subsection{Tissue Processing}

Immunohistochemical and immunofluorescence staining was performed on equal number of randomly selected tissue specimens from each organ.

Tissues from femoral cut down group were fixed in $4 \%$ paraformaldehyde in PBS ( $\mathrm{pH} 7.4$ ) overnight at $4^{\circ} \mathrm{C}$, rinsed in $15 \%$ sucrose for 24 hours at $4^{\circ} \mathrm{C}$, and embedded in optimal cutting temperature medium (OCT) (Tissue-Tek, Sakura Finetek, Torrance, $\mathrm{CA}$ ) and stored at $-80^{\circ} \mathrm{C}$. The embedded tissues were then 
made into sections to be examined with confocal fluorescent microscopy. The tissues from other three groups were fixed in formalin and embedded in paraffin to prepare paraffin sections. The sections were deparaffinized and proceeded for staining.

\subsection{Microscopy}

The uptake of control siRNA liposomes in different organs of femoral cut down was analyzed by confocal microscopy. The slides prepared as mentioned earlier were washed with PBS and counterstained with 4'-6'-diamidino-2-phenylindole (DAPI), which is a nucleic acid stain. The images from the femoral vein cut down method were observed with Leica TCS SP5 II microscope (Leica Microsystems, Mannheim, Germany). The tissues from tail vein, catheter and retro-orbital groups were analyzed by using Leica DM4000 microscope (Leica Microsystems, Mannheim, Germany). Fluorescent liposomes were quantitated manually in randomly selected tissue specimens.

\section{Results}

All animals survived to intended endpoints of seven days (tail vein [TV], femoral cut down $[\mathrm{FCD}]$ and percutaneous retro-orbital [PRO]) or three weeks (jugular catheterization [JC]). Of note, the JC group did not maintain catheterization for the entire study period. In spite of regular care and maintenance, only $3 / 10$ animals had intact catheter by the end of 3 weeks, and only $2 / 10$ of the animals were able to maintain dosing by the end of 4 weeks. We managed to repair the catheter to keep it intact for couple of days before it was broken. The mice with only intact catheters were considered for the study.

Dosing varied due to the route of administration. As noted, catheterized animals (JC) received three times the amount of liposomes of any of the other groups. Thus, the presence of fluorescent-labelled liposomes in JC liver and spleen (Figure 1) is the highest. In particular, the JC spleen tissue displays a higher level of accumulation (Figure 2). The three other administration routes display similar levels liposomal accumulation in the lung and liver despite the lower volume of liposomes administered through these routes (Figure 2, Table 4).

Table 4. Quantification of liposomal accumulation. Liposomes injected through different routes were taken up differently in livers, spleens and lungs. “+” indicates the extent of accumulation of liposomes.

\begin{tabular}{cccc}
\hline Route of Administration & Liver & Spleen & Lung \\
\hline Percutaneous retro-orbital & +++ & ++ & + \\
Jugular catheter & +++ & ++++ & + \\
Tail vein & +++ & ++ & + \\
Femoral cut down & +++ & ++ & + \\
\hline
\end{tabular}




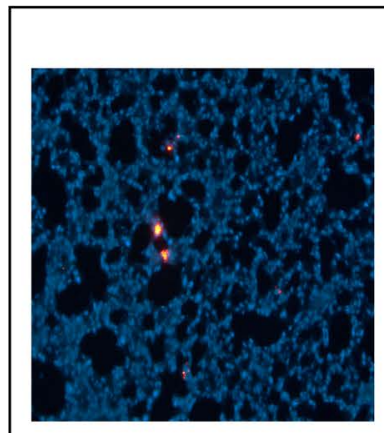

(a)

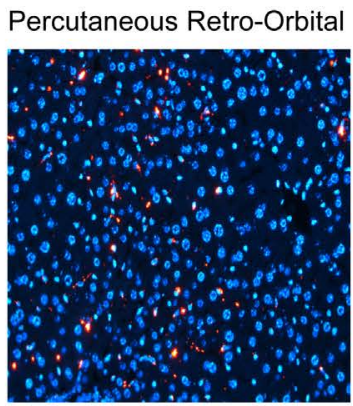

(b)

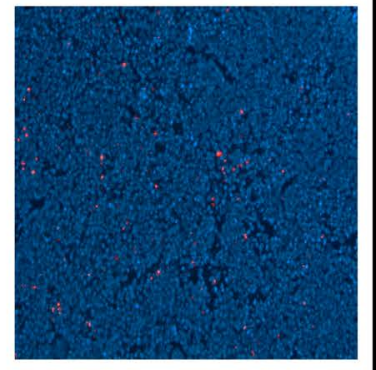

(c)

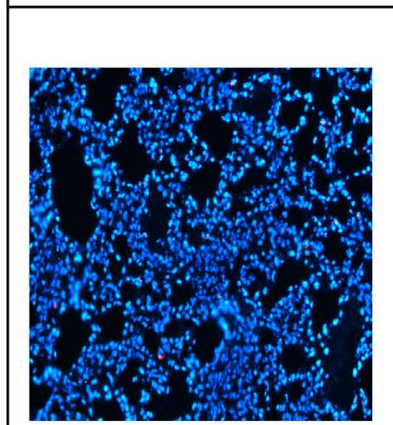

(d)

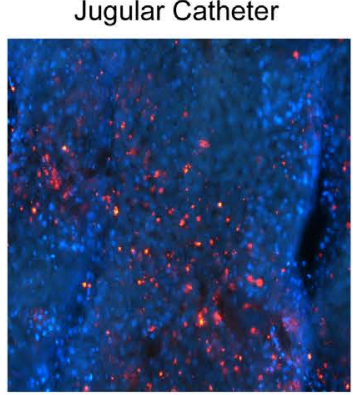

(e)

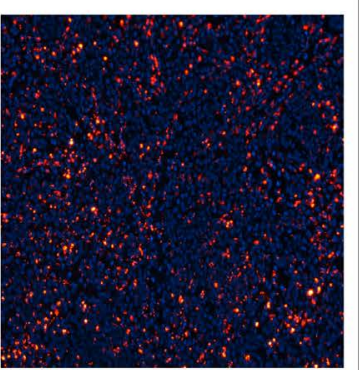

(f)

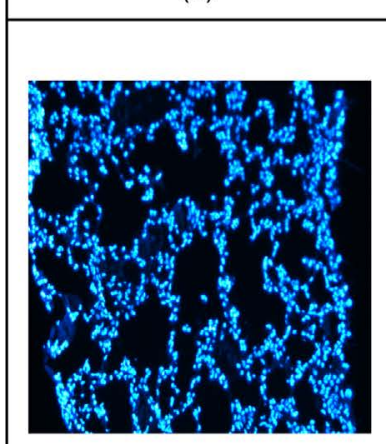

(g)

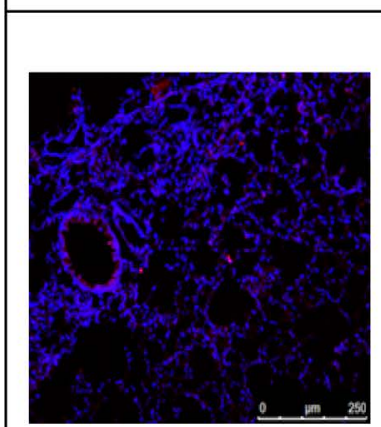

(j)

Tail Vein

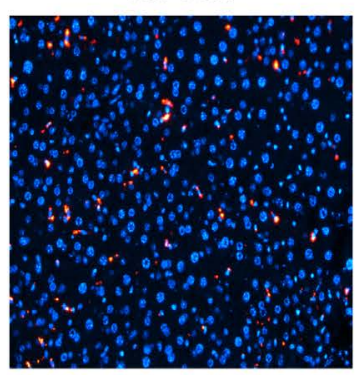

(h)

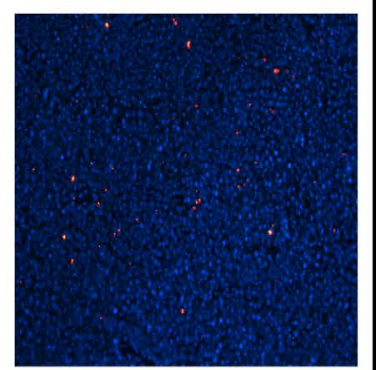

(i)

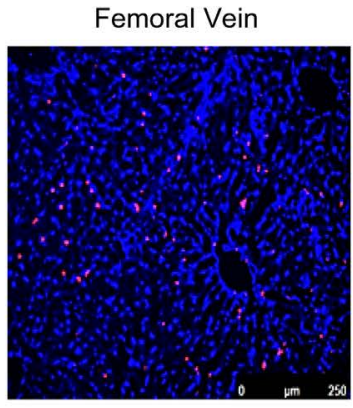

(k)

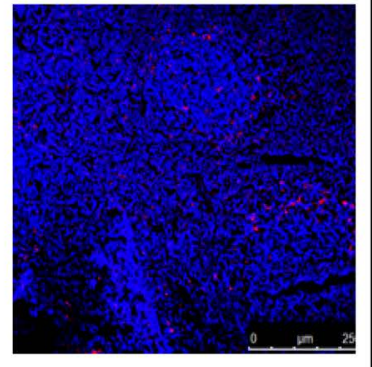

(I)

Figure 1. Distribution of liposomes in the different tissues of $A p o E^{-1-}$ mice by Percutaneous retro-orbital, jugular catheter, tail vein and femoral vein injections. Microscopy images (40× magnification) showed that red fluorescence from accumulation of QD liposomes was taken up differently into the tissues of $A p o E^{-1-}$ mice in different routes of administration. Liver (b) $>$ Spleen (c) > Lung (a), Spleen (f) $>$ Liver (e) $>$ Lung (d), Liver (h) $>$ Spleen (i) > Lung (g), Liver (k) > Spleen (l) > Lung (j) for per-cutaneous, Jugular, tail vein and Femoral cut down respectively. Blue: 4',6'-diamidino-2-phenylindole (DAPI) for nucleic acid stain. Red: QD-conjugated liposomal siRNA. 


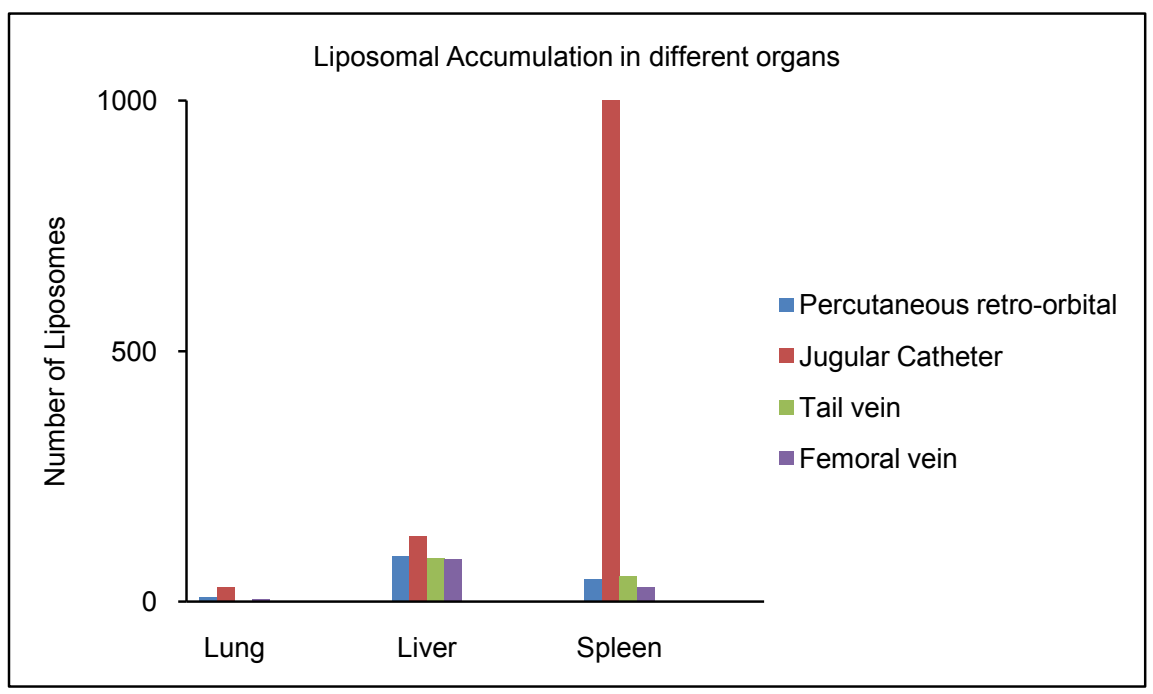

Figure 2. Graphical representation of the fluorescence intensity. The bar graph representing the fluorescence intensity of liposomal accumulation in different organs of per-cutaneous, jugular, tail vein and femoral cut down routes.

\section{Discussion}

Challenges associated with each of methods of delivery investigated here are associated with technique difficulty, volume limitations, rate of substance administration, and physicochemical properties of the substance itself [17]. When ranking technical difficulty, the PRO is the easiest to perform, followed by TV, FCD, and JC, respectively.

The JC group demonstrated a high accumulation of liposomes in the spleen, which would be useful when studying atherosclerosis or cancer treatments as the liposome vehicle can effectively target the macrophages in spleen before they terminally differentiate. Thus, macrophages could be pre-programmed in spleen before they get accumulated either in cancer cells and become tumor-associated macrophages or atherosclerotic plaques. The higher accumulation of liposomes in organs of the JC group is most likely due to the higher volume of liposomes that are able to be delivered. However, the surgery to insert the catheter presents both economical and technical challenges that supersede those of all of the other techniques compared herein. The fact that the majority of the catheters failed prior to the conclusion of the experiment demonstrates a significant hurdle to efficacy. In addition, the size of spleen was observed to be larger in the JC group. We hypothesize that the aggregation of liposomes in the spleen is due to the reticuloendothelial system actively trying to eliminate liposomes. Further research is needed to test this theory.

Animals should be closely monitored after the infusion for fluid overload and pulmonary edema [18]. There were no animals withdrawn from the study due to adverse events or injury.

Injections through tail vein or femoral vein have to pass through the liver to reach target organs such as heart, lungs and brain. Hence, liposomes may be fil- 
tered out during metabolism in liver, which decreases the amount of liposomes reaching the target tissue, making this route less ideal.

Percutaneous retro-orbital injections are reliable and easy route to administer substances into laboratory animals especially rodents with minimum incidences. Interestingly, in the PRO group, the highest concentration of liposomes was found in the liver. None of the PRO mice had any issues with the eye, which indicates successful administration without adverse events.

Considering the technical and economic challenges of each route and also from the experimental data, the PRO route was associated with the lowest technical challenge without losing the efficacy of delivery. We propose it to be the less expensive, more accurate, and effective route of injection.

\section{Limitations}

1) The number and age of the mice differed between the different groups of mice.

2) The higher dose of drug administered with the jugular catheterization might be responsible for the higher levels of liposome accumulation in the tissues.

3) Tissue preparation for mice injected via the femoral vein differed from other experimental groups.

\section{Acknowledgements}

We would like to thank Siqin Zhaorigetu for his technical contributions and Dr. Michelle Sauer for editorial assistance.

\section{Competing Interests}

AKS: Consulting (Merck, Kiyatec), shareholder (BioPath), and research funding (M-Trap).

\section{Funding}

This work was supported by the Gillson Longenbaugh Foundation (9091-001-N-1 \& G 2015).

\section{Conflicts of Interest}

The authors declare no conflicts of interest regarding the publication of this paper.

\section{References}

[1] Turner, P.V., Brabb, T., Pekow, C. and Vasbinder, M.A. (2011) Administration of Substances to Laboratory Animals: Routes of Administration and Factors to Consider. Journal of the American Association for Laboratory Animal Science, 50, 600-613.

[2] Yardeni, T., Eckhaus, M., Morris, H.D., Huizing, M. and Hoogstraten-Miller, S. 
(2011) Retro-Orbital Injections in Mice. Lab Animal (NY), 40, 155-160. https://doi.org/10.1038/laban0511-155

[3] Schoch, A., Thorey, I.S., Engert, J., Winter, G. and Emrich, T. (2014) Comparison of the Lateral Tail Vein and the Retro-Orbital Venous Sinus Routes of Antibody Administration in Pharmacokinetic Studies. Lab Animal (NY), 43, 95-99. https://doi.org/10.1038/laban.481

[4] Sucknow, M.A., Danneman, P. and Brayton, C.B. (2001) The Laboratory Mouse. CRC Press, Boca Raton. https://doi.org/10.1201/9780849376276

[5] The Jackson \& Laboratory. https://www.jax.org/jax-mice-and-services/find-and-order-jax-mice/surgical-and-p reconditioning-services/surgical-service-for-jax-mice/vascular-care-and-use

[6] Jones, C.P. and Dubuque, J.R. (2015) Percutaneous Retro-Orbital Injections in Mice. Laboratory Animal Science Professional.

[7] Jerebtsova, M., Liu, X.H., Ye, X. and Ray, P.E. (2005) Adenovirus-Mediated Gene Transfer to Glomerular Cells in Newborn Mice. Pediatric Nephrology, 20, 1395-1400. https://doi.org/10.1007/s00467-005-1882-0

[8] Jerebtsova, M., Ye, X. and Ray, P.E. (2009) A Simple Technique to Establish a Long-Term Adenovirus Mediated Gene Transfer to the Heart of Newborn Mice. Cardiovascular \& Hematological Disorders-Drug Targets, 9, 136-140. https://doi.org/10.2174/187152909788488645

[9] Price, J.E., Barth, R.F., Johnson, C.W. and Staubus, A.E. (1984) Injection of Cells and Monoclonal Antibodies into Mice: Comparison of Tail Vein and Retroorbital Routes. Proceedings of the Society for Experimental Biology and Medicine, 177, 347-353. https://doi.org/10.3181/00379727-177-41955

[10] Steel, C.D., Stephens, A.L., Hahto, S.M., Singletary, S.J. and Ciavarra, R.P. (2008) Comparison of the Lateral Tail Vein and the Retro-Orbital Venous Sinus as Routes of Intravenous Drug Delivery in a Transgenic Mouse Model. Lab Animal (NY), 37, 26-32. https://doi.org/10.1038/laban0108-26

[11] Tal Yardeni, C.C., Hoogstraten-Miller, S., Darvish, D., Anikster, Y., Maples, P., Jay, C., Gahl, W.A., Nemunaitis, J. and Huizing, M. (2010) A Non-Viral, GNE-Lipoplex Treatment to Correct Sialylation Defects in Gne-Mutant (M712T) Mice. American Society of Gene Cell Therapeutics 2010 Annual Meeting, Washington DC, Abstract $\# 144$.

[12] Song, H., et al. (2010) Mammalian Mst1 and Mst2 Kinases Play Essential Roles in Organ Size Control and Tumor Suppression. Proceedings of the National Academy of Sciences of the United States of America, 107, 1431-1436. https://doi.org/10.1073/pnas.0911409107

[13] Walton, B.L., et al. (2010) Delivery of Negatively Charged Liposomes into the Atheromas of Watanabe Heritable Hyperlipidemic Rabbits. Vascular Medicine, 15, 307-313. https://doi.org/10.1177/1358863X10374118

[14] Zhaorigetu, S., Prathipati, P., Rodriguez-Aguayo, C., Walton, B.L., Sood, A.K. and Berestein-Lopez, G. (2019) Fatty Acid Binding Protein-4 Silencing Attenuates Atherosclerosis Progression by Affecting Macrophage Apoptosis and Autophagy. Journal of Biosciences and Medicines, 7, 99-109. https://doi.org/10.4236/jbm.2019.77008

[15] Sharp, P. and Regina, M.L. (1997) The Laboratory Rat. CRC Press, Boca Raton.

[16] Pekow, C. and Baumans, V. (2003) Common Nonsurgical Techniques and Procedures. In: Hau, J., Schapiro, S.J. and Van Hoosier, G.L., Eds., Handbook of Labora 
tory Animal Science, 2nd Edition, Vol. 2: Animal Models, CRC Press, Boca Raton, 351-391. https://doi.org/10.1201/9781420040913.ch15

[17] Morton, D.B., et al. (2001) Refining Procedures for the Administration of Substances. Report of the BVAAWF/FRAME/RSPCA/UFAW Joint Working Group on Refinement. British Veterinary Association Animal Welfare Foundation/Fund for the Replacement of Animals in Medical Experiments/Royal Society for the Prevention of Cruelty to Animals/Universities Federation for Animal Welfare. Lab Animal, 35, 1-41. https://doi.org/10.1258/0023677011911345

[18] Mazzaferro, E.M. (2008) Complications of Fluid Therapy. Veterinary Clinics of North America: Small Animal Practice, 38, 607-619.

https://doi.org/10.1016/j.cvsm.2008.01.003 